\title{
Satellite solar wireless power transfer for baseload ground supply: clean energy for the future
}

\author{
Kalpana Chaudhary and Deepak Kumar
}

\begin{abstract}
Many factors are influencing the acceptability of energy technology. The transformation of the energy sector is looking for clean energy technology that is also suitable for baseload power generation. Terrestrial solar energy has many obstructions, so solar power from space without any hindrance has higher priority for adoption, and it is suitable for future energy continuous demand supply. As technology is advancing, the possibility of satellite solarbased power station is more than a science fiction now and is possible in the coming future. Microwave transmission with high beam efficiency is the key issue to be improved for the feasibility of satellite solar power station. Besides others, research should focus on the reduction of space segment's components dimension and space vehicle dispatch cost. Concerning space segments, applying an optimized value of fractional power unit modules and assembling it for constant baseload power supply have economic advantages, as well as that the antenna size is also reduced. This work deals with system components size estimation and optimization for a selected 10-GW baseload power supply. Four case studies have been conducted considering the different unit sizes, and the system model is analyzed for suitable power unit selection.
\end{abstract}

Keywords: Energy technology, Energy transformation, Satellite Solar Power Station, Microwave technology

\section{Introduction}

World energy demand is increasing continuously, and it is expected to grow multiple times by 2040 [1]. It is because the expectation for everyday comforts and the number of inhabitants in developing nations is increasing. The need to come up with sources of green energy for sustainable development has emerged to provide the society with comfort, shelter, and future security [2]. The question arises: Will the clean energy transformation be fast enough to fulfill the world energy demand for the coming decades in time?

There are fields like communication technology and biomedical research where transformation is happening at much higher pace, and due to highly competitive markets, customers are benefited with quality products at a reduced cost [3]. Can we expect the same transformation rate in energy sectors market? Even though governments worldwide are making policies and motivating

\footnotetext{
* Correspondence: deepak.rs.eee14@itbhu.ac.in

Department of Electrical Engineering, Indian Institute of Technology, BHU, Varanasi, India
}

clean energy transformation, it is not enough to achieve the goal $[4,5]$. There are many reasons behind the moderate energy transformation. One of the essential issues is, there is no competition among energy sector markets or competition with low-profit margin, so they are not bothered adopting new technology. There are structural features in the real energy system that slows down or even prevents technology change, so there are chances that energy transform may not happen at the pace as required [6]. The future energy system based on clean energy technology is shown in Fig. 1. For the stationary usage, modernizing the grid with renewable resources is the primary goal. Also, energy use in transport sector must employ alternatives to hydrocarbon fuels, which requires low-cost electric vehicles with high efficiency. To modernize the power grid with clean energy technology, the behavioral impact from customers is extremely important and interdisciplinary studies that are collaborative, open, and global are critically needed. Energy transform discussion has a variety of issues which can only be addressed utilizing social science and behavioral 


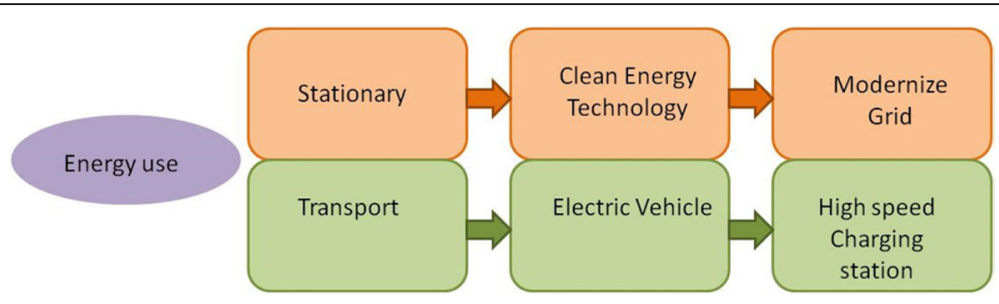

Fig. 1 Energy technology innovation

research. Here we will have to understand that energy sector market is non-competitive. Thus, they are not responding to technology development or in many cases they are reluctant to transformation [3, 4]. Consumers are not concerned with the source of energy if they will have to pay the same electricity bill. The idea of long-term benefit is still alien to customers in the energy sector as they are only concerned with the cost and reliability [7]. Therefore, in the area of energy production and use, there is a requirement of social science expertise. It is required to understand better the role of public attitude, economic trends, and government regulations in the development and adoption of clean energy [3-5].

In the stationary energy system, sources providing baseload capacity (continuous power supply) are given higher priority for energy transformation over intermittent power sources [1]. Unfortunately, most of the renewable energy sources being utilized for power supply are experiencing irregular power production, and they require additional storage units [8]. Recently, most of the industry and institutional work is focused on the adoption of terrestrial solar energy. The research is concentrated on the potential effects of distributed power generation or grid integration for both solar photovoltaic and solar thermal power stations [8]. However, there are challenges in adoption of terrestrial solar energy. For example, solar photovoltaic and solar thermal can supply power only in the daytime, and solar irradiance fades on cloudy and stormy days. The other negative point with solar panels or solar thermal energy is that it needs regular care and maintenance. In solar photovoltaics, it is a key issue because pollution and dirt can degrade photovoltaic efficiency or electrical power production.

On the other hand, among the accessible renewable energy resources, space-based solar energy is most promising as it can provide 24-h energy demand [8]. Therefore, it is a suitable energy source that can promote sustainable development of humankind. It is a proper aspirant which assures a practical and carbon dioxide-free energy, convenient for continuous power supply or baseload supply. There are several advantages which have propelled investigation into satellite solar power station (SSPS) to modernize the grid. In SSPS, there is no hindrance to the solar flux by the surrounding environment of the earth as shown in Fig. 2. A SSPS constitutes a technique for collecting space solar power utilizing satellites and transporting it to the ground wirelessly by utilization of microwaves $[9,10]$. In many aspects, SSPS has advantages over terrestrial solar power due to unobstructed and undistorted solar irradiance available in space [9]. Furthermore, the SSPS has a three-fold increase in power accessibility over the terrestrial solar power system [9].

From 1970, US space agency NASA (National Aeronautics and Space Administration) in collaboration with DOE (Department of Energy) has been working on SSPS for power generation on earth [11]. The combined effort came up with the proposed model of SSPS 5-GW baseload power capacity at $2.45 \mathrm{GHz}$ working frequency [12]. Unfortunately, due to the high costs and a lack of funding, the research has been suspended in 1980. After that, space agencies around the globe are trying to reduce estimated initial cost for SSPS. A Sun Tower model has been proposed with many improvements [12]. The integrated symmetric concentrator has been proposed later with high solar collection efficiency. Several agencies also proposed a model with efficient heat dissipation. Japan's space agency JAXA (Japan Aerospace

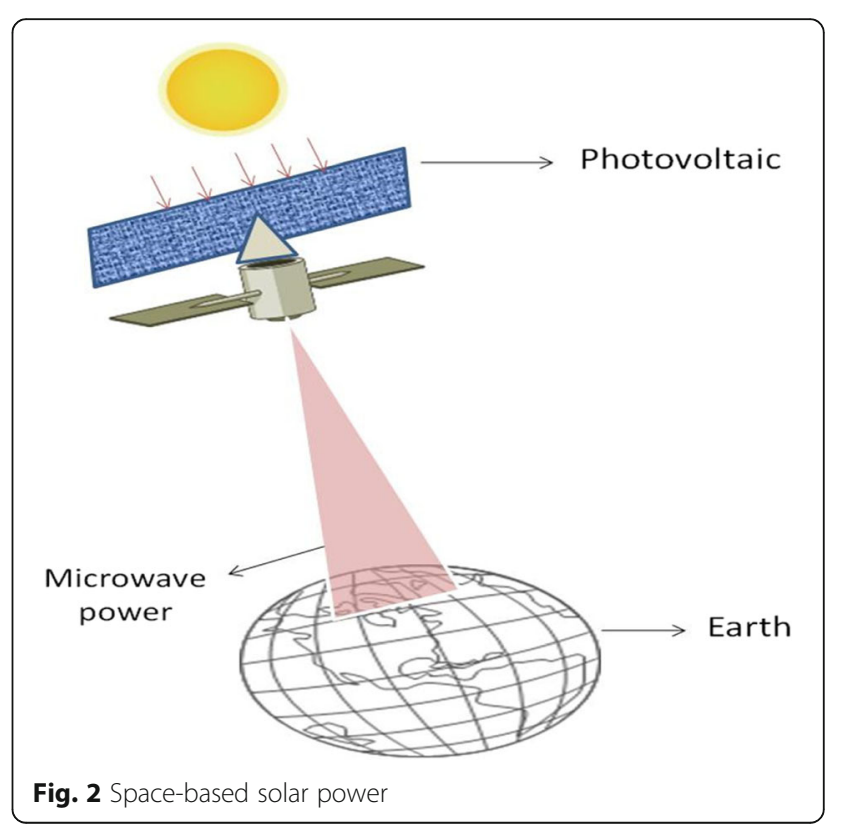


Exploration Agency) is developing a SSPS prototype model for pilot demonstration at $5.8-\mathrm{GHz}$ working frequency [1].

This work proposes a 10-GW SSPS model for baseload power generation. The model is based on SSPS in the geosynchronous orbit $(36.000 \mathrm{~km})$. A large size antenna on earth is required for collecting microwave power. The ground antenna integrated rectifiers will convert the microwave power into electrical energy. For 10-GW baseload power from space, a single SSPS unit is not practically feasible. An optimized size of smaller power capacity units is required, that will collectively supply 10 GW power. Here the transmitting antenna size (space part) depends on the unit's power capacity, so an optimized selection is necessary. For calculating the size of the transmission antenna, a case study analysis is performed to demonstrate $10 \mathrm{GW}$ SSPS models. In this work, four cases with different unit power capacity have been considered that will provide $10 \mathrm{GW}$ baseload power (each case). For transportation, in the first stage, the satellites will be installed in low earth orbit $(900 \mathrm{~km})$ using reusable launch vehicle. Furthermore, it will be transferred to the geosynchronous orbit utilizing Orbital Dispatch Vehicle.

\section{SSPS research worldwide}

Broadly speaking, the principal idea of SSPS was envisioned by P. Glaser in the year 1968 [9, 13]. He proposed SSPS after a progression of analyses on Wireless Power Transmission. Following Glaser, the USA directed an extensive practicality revision scope during 1978 and 1980 [8]. The possibility study has been a collaborative exertion of NASA and DOE. Both jointly suggested an enhanced model well-known as a reference model in the year 1979 (see Fig. 3 (a)) [1]. The model projected a SSPS 5-GW baseload power plant.

The SSPS exploration was interrupted in the USA in the year 1980 due to its high budget. However, due to its high potential to modernize the grid, it was generally assessed applicable for future baseload power generation. In the progression of the SSPS concept, the "Fresh Look" Space-based Solar Power idea was proposed in the year 1997 as an enhanced SSPS reference framework [1]. Figure $3 \mathrm{~b}$ shows the Sun Tower SSPS model. It was among the best innovative designs and endeavors various innovative ways that deal with SSPS progress. Through lessening the total life-cycle cost $[8,14]$, it proposes a widening market adaptability for the future energy transformation.

The abovementioned Sun Tower-based SSPS idea is based on satellites of standard size, which are merely connected in a balanced structure through a specific gravity slope. It has an inbuilt microwave generator and transmitter based on space solar power construction. Each satellite looks like a large sunflower directed towards earth. In the structure, the blossoms in their appearance exhibit transmitter arrangements and the leaflets on the trail are sun power accumulators. The idea is expected to transfer microwave energy at frequencies 2.45 or $5.8 \mathrm{GHz}$ from an introductory equipped LEO orbit of $900 \mathrm{~km}$ altitude with a performing sun-synchronous focus to deliver 200-MW microwave power on earth. Complete beam guiding capacity is kept at $60^{\circ}$. The heat dismissal for energy transformation and molding frameworks is thought to be collected in small units, and for that reason, coordination with energy transformation frameworks is required [1]. On account of the

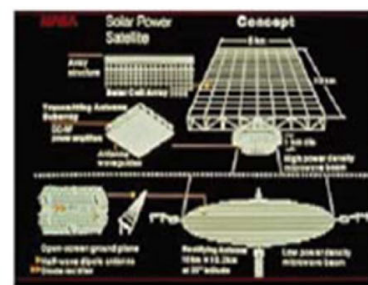

a

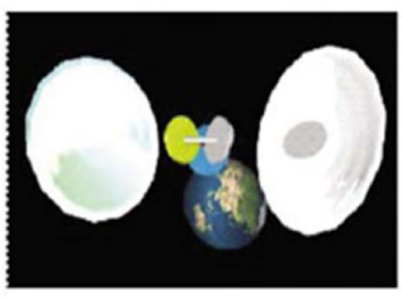

d

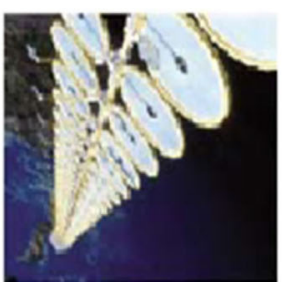

b

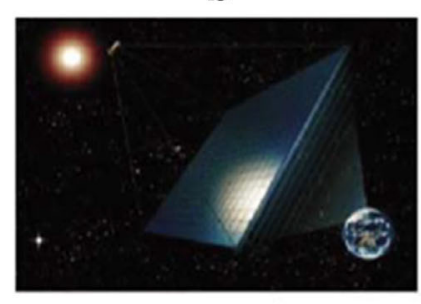

e

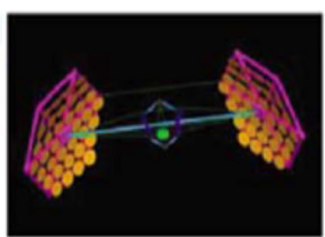

C

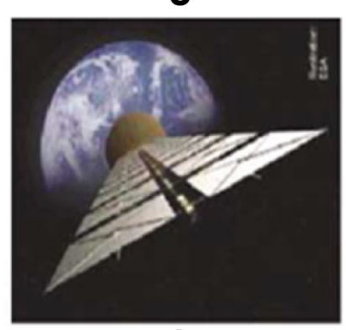

f

Fig. 3 a-f Different SSPS reported models [1] 
microwave transmitter, heat removal is considered at the rear plane of the antenna cluster. The lines of power transmission are instigated from a single focal tie or tether connection point on the rear side; those are incorporated coordinately with the unit sub-arrays of the cluster.

A model, integrated with the symmetric concentrator, as illustrated in Fig. 3c, was proposed with high solar collection efficiency. In this model, two giant similar clam shells consist of mirrors. Every planar mirror is around 400-m distance apart. The structure was build up on the rear plane side at a marginally distinctive point to shape a fragmented clamshell mirror. While the symmetrical concentrator and the integrated structure do not use in between optical reflection imaging, every mirror's reflection of sunlight just needs to drop anywhere on the solar PV cluster. A mounting structure is required with an objective to avoid hotspot areas. The pole length is estimated such that the axial mirror collector's length is more than $10 \mathrm{~km}$ [1]. The large focal length offered a reasonable solar spot size by creating the sun's picture on the solar collectors. An underlying integrated structure symmetrical concentrator idea provides the design flexibility of the solar clusters on the rear plane of the transmitter. In this way, power cabling separations are highly reduced, and the back sides of either the solar array or the microwave transmitter structure can be used for radiating heat.

The JAXA (Japan Aerospace Exploration Agency) unit is focusing on SSPS and has assessed feasibility at various constituents levels [1]. They suggest that it is conceivable to beam space solar power and transfer to earth by utilizing microwave transmission or a laser forming technique. However, microwave transmission is gaining particularly popularity. It is because the optical strategies perpetually comprise climate associated reduction or because of the ionization problem. In the year 2001, JAXA has planned a 1-GW SSPS JAXA demonstration model utilizing microwave transmission at the $5.8-\mathrm{GHz}$ frequency. A variety of designs have been technically amended, practically assessed and recommended. These are not quite the same as the NASA/DOE model [8]. While concerning SSPS heat-related problems, an improved structure must contain both the solar array and the transmitting antenna on the same sun facing plane. Here powered solar arrays and transmission antenna exist collectively on the front surface with adjustment one next to the other. The rear is freely available for heat dissipation. In other words, it can be said that the radiation operation, i.e., solar power gathering and radio wave transmission, happens on the front side, and undesirable heat will be dissipated from the opposite side as outlined in Fig. 3d.
Later on, the Institute for Unmanned Space Experiment Free Flyer (USEF) proposed a tethered model of SSPS shown in Fig. 3e. In this framework, the model lacks in sun tracking. That is why, the average power productivity is reduced by $35 \%$ compared to the NASA/ DOE reference design [1]. Though, the basic idea involved in this model advances with a resolution for all the technical challenges in past SSPS models. The nonappearance of a stirring structure for a substantial scale validates that the framework is exceedingly vigorous and stable. However, that fact that a radiance concentrator was not utilized for solar collectors is a negative point. Furthermore, a massive section of surface is required for capturing sunlight. The positive point is that heat dissipates effortlessly into space without any dynamic thermal control [8]. In any case, the SSPS system is large, and it is practically possible only with a reusable space launch vehicle (RSLV) system [13, 15].

\section{SSPS as base-load power plants}

The base-load power plant is essential for the rising energy demand. Terrestrial solar power is a clean source of intermittent power supply, yet it is not reasonable for base-load power [10, 16]. The advantage of SSPS technology is, it can be used for base-load request.

For providing base-load power, placing a large satellite in the geosynchronous orbit is most sensible. However, this idea is full of technical challenges, as the SSPS is gigantic and it will be developed for a limited period as the estimated life cycle of SSPS is about 30 years. Therefore, its cost cannot be evaluated with the present day's transportation framework [2]. As a prerequisite, two sorts of vehicles have to be developed: one for the transportation and one for assembling the SSPS. The main sort is a Reusable Launch Vehicle that will transport SSPS segments to a low earth orbit. It will offer sensible negligible exertion; transportation cost and further assembly will be performed in this orbit $[2,8,14]$. At that point, an Orbital Dispatch Vehicle will be required to raise the SSPS from the low earth orbit to geo orbit. A space vehicle technology consolidating both rocket types is required for the deployment of the SSPS framework, as well as a novel, cost-effective rocket to dispatch heavier weight to low earth orbit. At present, space vehicle transport technology has been contemplated without any thought of SSPS. Therefore, there are requirements of 3rd generation Reusable Launch Vehicles aiming for SSPS. As well, there is also a requirement of broad size rectenna on Earth [17] to receive power from space. The rectenna mounted ground is free for agribusiness and may be utilized for different purposes [9, 18]. With technological advancement, SSPS power cost could be reasonable or less than various earth-based energy 
resources. With the progression to reduce the satellite dispatch cost and supplementary innovation changes, SSPS seems to be feasible in the coming future. Creative progress in microwave advancement is going ahead around the globe in this way.

This work is an assessment of SSPS research and development as a base-load power. The reference framework was chosen by the US space research agency (NASA and US DOE 1978). In this framework, space satellites collect sun irradiance and photovoltaic transform the acquired sun power into electrical energy (DC power). The high voltage DC power is subsequently supplied to microwave generators, i.e., magnetron intended to deliver the microwave power [13]. The beam formation is achievable using phased array antenna or slotted waveguides. In this way, the electrical power changes into the microwave and after beamforming transfer this microwave power to a specific receiving location on earth. The receiving microwave antenna associated with rectifiers turns over the high-frequency microwave energy back to electrical power. This way, the space energy is obtainable on earth to supply the commercial grid after appropriate power management [5]. In this model, the $100-\mathrm{km}^{2}$ solar array collects around 104.4 GW of space solar insolation of $1370 \mathrm{~W} /$ $\mathrm{m}^{2}$ at geostationary orbit and creates 20.9-GW DC power ( $20 \%$ conversion efficiency). This framework delivers microwave energy of $14.61 \mathrm{GW}$ at $2.45 \mathrm{GHz}$ from a large radius transmitter or reception apparatus $(90 \%$ beam proficiency). With a specific end goal to acquire better power accumulation efficiency, there is a proper Gaussian beam in $10 \mathrm{dBm}$ range, which is acceptable for radial distribution of power in the reception apparatus or antenna [19]. On the ground segment, a $10-\mathrm{km}^{2}$ antenna site gathers $10 \mathrm{GW}(87 \%$ power accumulation effectiveness). The SSPS ground antenna would have 100 million components in array structure with a component separating of more than $0.5 \lambda[13$, 20]. This power is delivered to the utility network. The power flow diagram is outlined in Fig. 4.

\section{Transmitting antenna size estimation for SSPS 10- GW model}

For 10-GW baseload power from space, a single SSPS unit is not practically feasible. An optimized size of smaller power capacity units that will collectively supply $10-\mathrm{GW}$ power is required. Here the transmitting antenna size (space part) depends on the unit's power capacity, so selection must be wisely made. For the calculation of the transmission antenna size, a case study analysis is performed to demonstrate 10-GW SSPS models. In this work, four cases with different unit power capacities have been considered that will provide 10-GW baseload power (each case).

Case 1: Cnsideration of 50 units of 200-MW SSPS module.

Case 2: Consideration of 20 units of 500-MW SSPS module.

Case 3: Consideration of 10 units of 1-GW SSPS module.

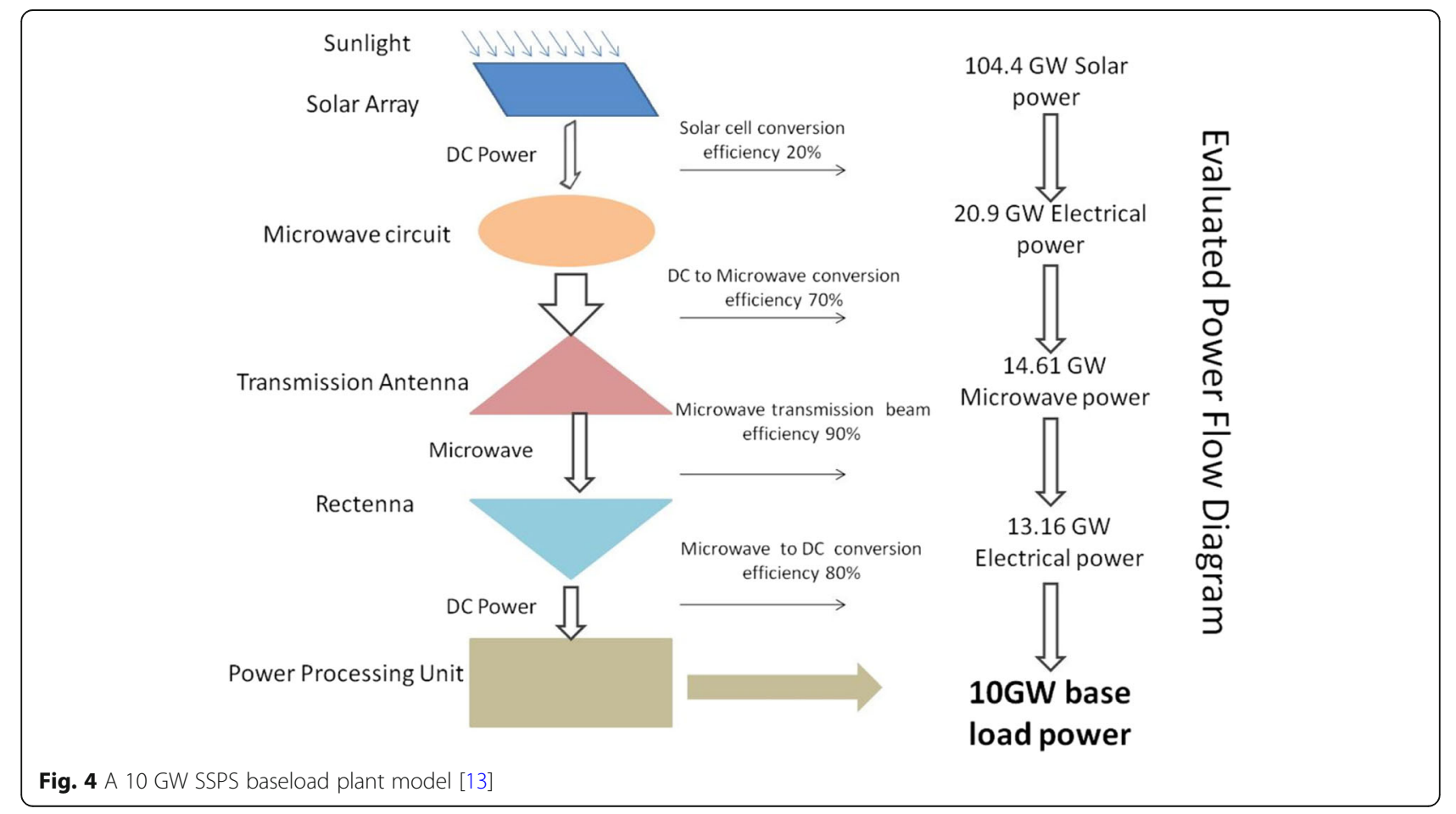




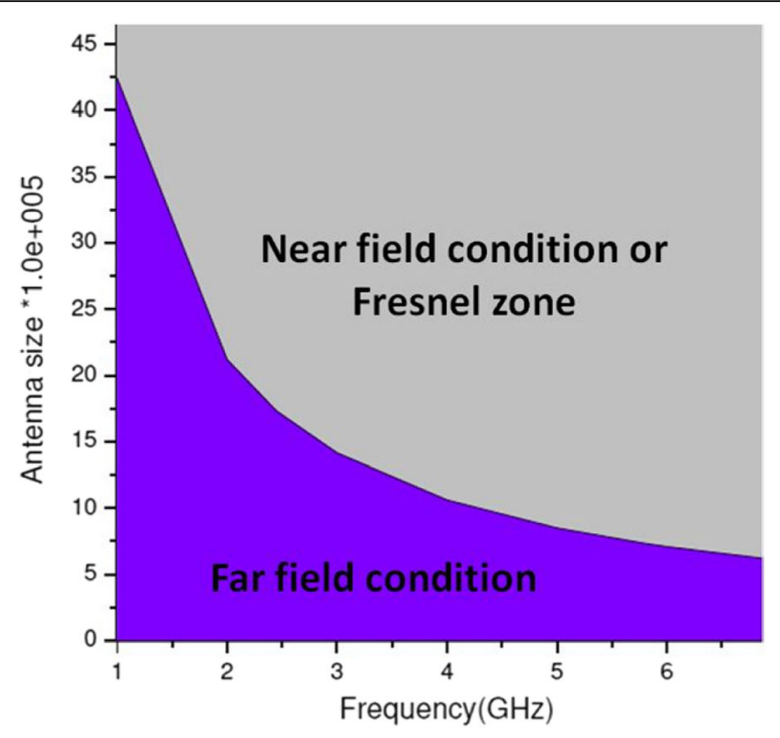

Fig. 5 Antenna size $\left(\mathrm{m}^{2}\right)$ variation with frequency and near-field region

Case 4: Consideration of 4 units of 2.5-GW SSPS module.

$$
\begin{aligned}
& \frac{P_{r}}{P_{t}}=\frac{A_{t} A_{r}}{\lambda^{2} D^{2}}=\tau^{2} \\
& P_{t}=\frac{P_{d} \lambda^{2} D^{2}}{A_{t}} \\
& \eta_{\text {beam }}=1-e^{-\tau^{2}}
\end{aligned}
$$

Friis reformed transmission equation, which is given in Eq. (1) [21], is used to find a relation between transmitted power $\left(\mathrm{P}_{\mathrm{t}}\right)$ and received power $\left(\mathrm{P}_{\mathrm{r}}\right)$ for a specified distance (D) and the working wavelength $\lambda$. Here $A_{t}$ and $A_{r}$ are an effective surface of transmitting antenna and receiving antenna respectively. Equation (1) can be rearranged as in Eq. (2), where $P_{\mathrm{d}}$ is power density on the receiving antenna. According to microwave safety and security limit, microwave power density in earth atmosphere must be below $100 \mathrm{~W} / \mathrm{m}^{2}$. For microwave power transmission, we

Table 1 Antenna size $\times 10^{5} \mathrm{~m}^{2}$ at $5.8 \mathrm{GHz}$ with different beam efficiency

\begin{tabular}{lllllllll}
\hline Case & $\begin{array}{l}\text { Unit } \\
\text { size }\end{array}$ & \multicolumn{6}{c}{ Beam efficiency } \\
\cline { 3 - 9 } & 0.8 & 0.82 & 0.84 & 0.86 & 0.88 & 0.9 & 0.92 \\
\hline 1 & $200 \mathrm{MW}$ & 27.863 & 29.687 & 31.727 & 34.038 & 36.707 & 39.864 & 43.727 \\
2 & $500 \mathrm{MW}$ & 11.145 & 11.875 & 12.691 & 13.615 & 14.683 & 15.945 & 17.491 \\
3 & $1 \mathrm{GW}$ & 5.5727 & 5.9375 & 6.3453 & 6.8077 & 7.3414 & 7.9727 & 8.7453 \\
4 & $2.5 \mathrm{GW}$ & \multicolumn{7}{c}{ Not possible size (near field zone constraints) } \\
\hline
\end{tabular}

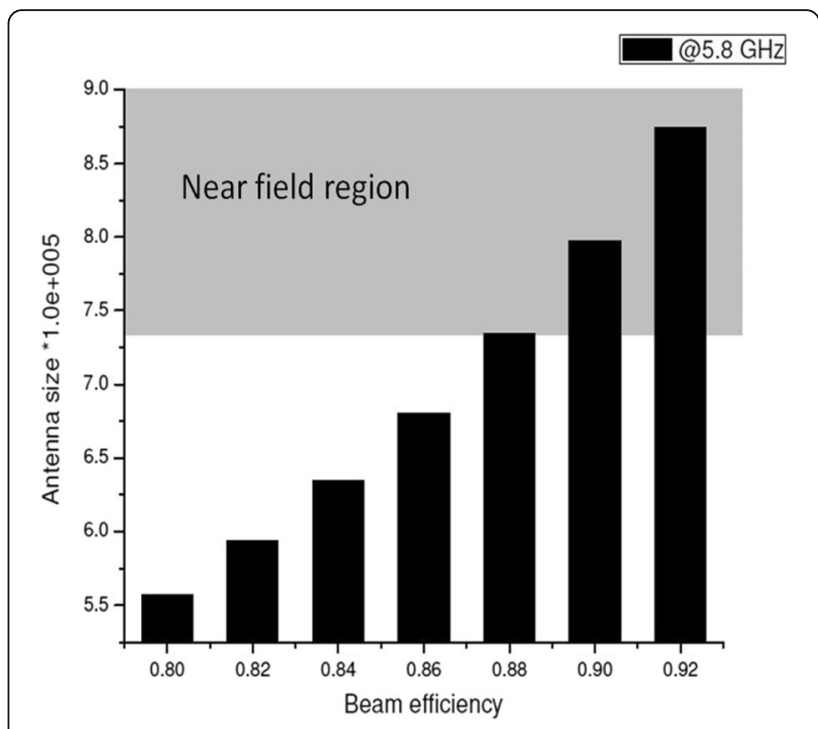

Fig. 6 Antenna size $\left(\mathrm{m}^{2}\right)$ variation with Beam efficiency at $5.8 \mathrm{GHz}$ for case 3 (1-GW unit)

are considering Gaussian beamforming, the beam efficiency given in Eq. (3). From Eq. (2), one can easily analyze that lower size transmitting antenna has higher power transmission capacity. But there is a restriction from the near field condition for microwave beamforming. There is also frequency reliance on the microwave power transfer. Two space research groups, NASA (USA) and JAXA (Japan), have proposed different working frequency for feasible satellite solar power implementation, i.e., 2.45 and $5.8 \mathrm{GHz}$ respectively [1]. Therefore, a unit-wise case study will make an advanced observation for a cost-effective

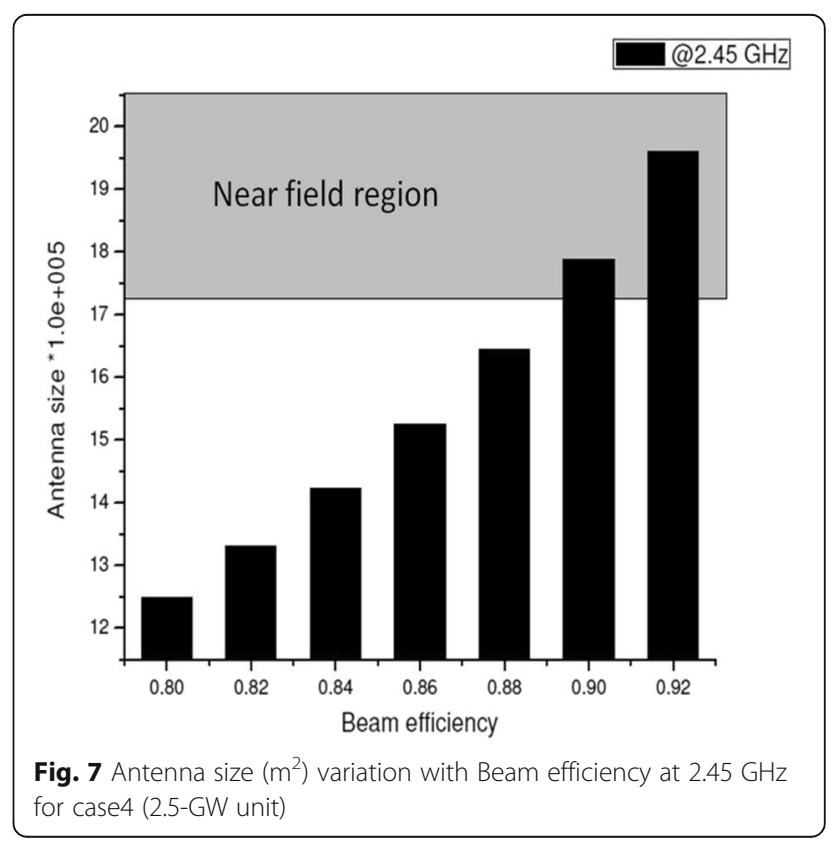


SSPS demonstration with optimized transmitting antenna size.

Case $4<$ case $3<$ case $2<$ case 1 (considering same working frequency).

Bringing down transmitting antenna size with more power transmission capability, it is only possible at a higher frequency. It is shown in Fig. 5 that as the working frequency increases the required transmitting antenna size is reduced for near field region. Here two frequencies 2.45 and $5.8 \mathrm{GHz}$ have been selected for SSPS prototype demonstration because these are the frequencies that lie in the atmospheric window.

\section{Results and discussion}

\section{Working frequency $5.8 \mathrm{GHz}$}

In all cases considered above, the deviation in transmitting antenna dimension at $5.8-\mathrm{GHz}$ frequency for different beam collection efficiency is provided in Table 1 . Here one can rapidly explore that a changed beam efficiency has an immediate effect on the receiving antenna size. For instance in case 1, which is the minimal power unit in this study, which requires a reasonably higher size. In case 3 with a 1-GW unit, the necessary size is lower. However, beam efficiency below $88 \%$ is not a feasible condition. Besides, the further decrease in the size is obviously confined by near-field condition constraint. Therefore, one can conclude that 1-GW unit size with $88 \%$ beam collection efficiency will provide the optimized transmitting antenna size for $10-G W$ SSPS prototype. The antenna size variation with beam efficiency is plotted in Fig. 6, which offers a clear picture of the near-field boundary.

\section{Working frequency $2.45 \mathrm{GHz}$}

The deviation in transmitting antenna dimension at $2.45-\mathrm{GHz}$ frequency for different cases is characterized in Table 2. At this frequency, near to far field transition boundary situation is present in case 4, i.e., 2.5-GW individual power units. The higher beam efficiency also requires a larger size and the transmitting antenna size requirement for case 1 is the highest. Antenna size requirement with beam efficiency variation for case 4 is given in Fig. 7. In case 4 , which is 2.5-GW units, size requirement is lower, but the

Table 2 Antenna size $\times 10^{5} \mathrm{~m}^{2}$ at $2.45 \mathrm{GHz}$ with different beam efficiency

\begin{tabular}{lllllllll}
\hline \multirow{2}{*}{\begin{tabular}{l} 
Case \\
Size \\
\cline { 3 - 9 }
\end{tabular}} & 0.8 & 0.82 & 0.84 & 0.86 & 0.88 & 0.9 & 0.92 \\
\hline \cline { 3 - 9 } & $200 \mathrm{MW}$ & 15.616 & 16.638 & 17.781 & 19.076 & 20.572 & 22.341 & 24.506 \\
2 & $500 \mathrm{MW}$ & 6.2462 & 6.6551 & 7.1123 & 7.6305 & 8.2288 & 8.9363 & 9.8024 \\
3 & $1 \mathrm{GW}$ & 3.1231 & 3.3276 & 3.5561 & 3.8152 & 4.1144 & 4.4682 & 4.9012 \\
4 & $2.5 \mathrm{GW}$ & 1.2492 & 1.3310 & 1.4225 & 1.5261 & 1.6458 & 1.7873 & 1.9605 \\
\hline
\end{tabular}

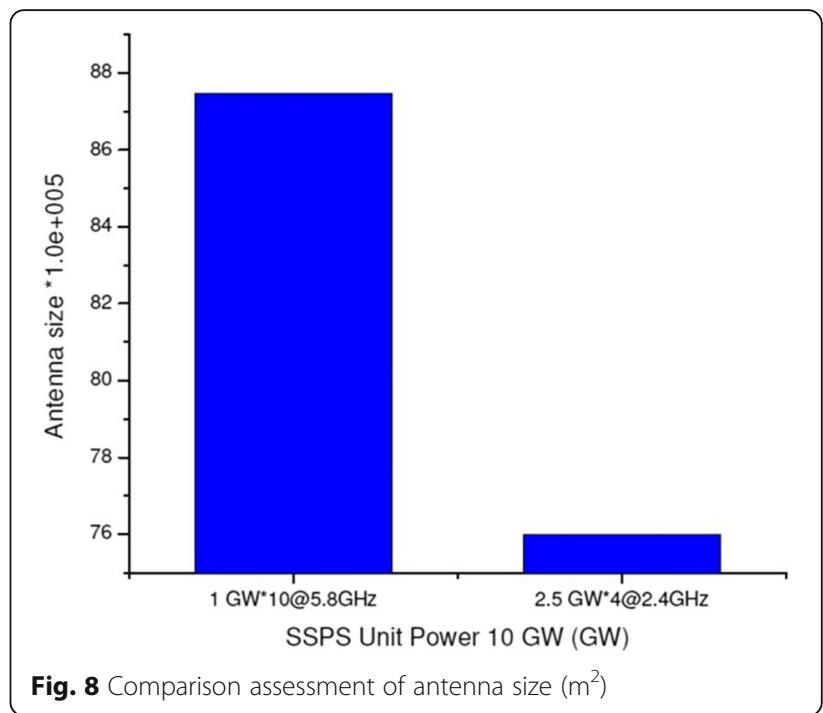

beam efficiency below $90 \%$ is not a feasible condition. Therefore, one can conclude that the $2.5 \mathrm{GW}$ unit using a transmitting antenna with $90 \%$ beam collection efficiency will provide the optimized size. Also, a further decrease in size is strongly restricted by near-field condition limit.

\section{Optimized transmitting antenna estimates for 10-GW power}

Up to this point, results are derived for transmitting antenna estimation at $5.8-\mathrm{GHz}$ operating frequency. For this, case 3 , lies in the boundary zone, and for a beam efficiency greater than $88 \%$, the SSPS is feasible. Subsequently, at $2.45-\mathrm{GHz}$ working frequency, the boundary zone is now extended to case 4, and the beam efficiency at the border is $90 \%$. For the higher power unit, $2.45-\mathrm{GHz}$ frequency has extended near

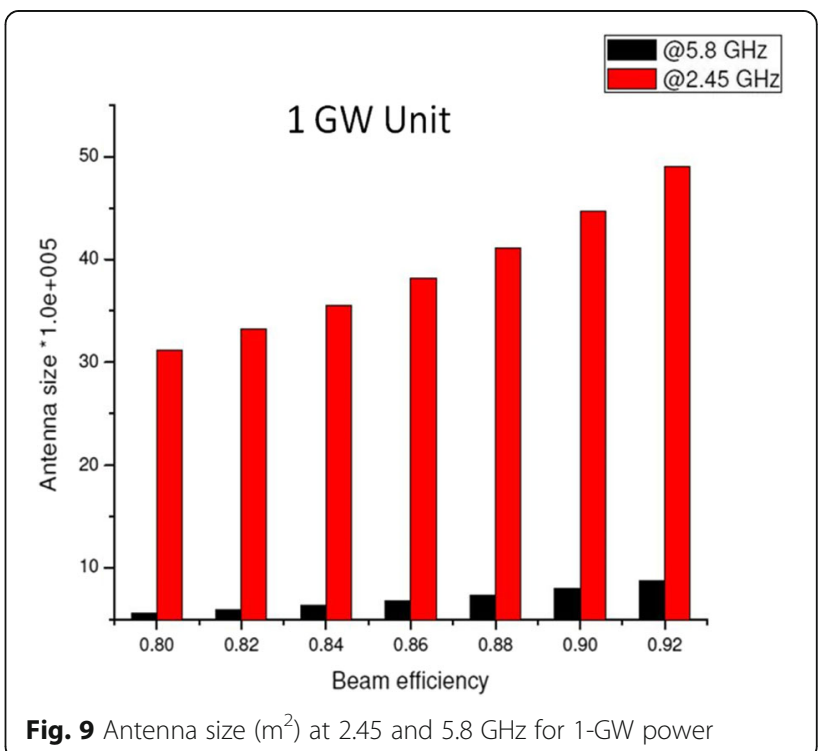


field constraint. The transmitting antenna size plays an important role in the main goal of cost effectively transmitting 10-GW power from space to earth. Therefore, an overall comparison is necessary for the suitable frequency selection for the high power transmission. Considering the boundary condition as abovementioned, the required transmitting antenna size for $10-\mathrm{GW}$ power at the frequencies 2.45 and $5.8 \mathrm{GHz}$ are compared, as shown in Fig. 8. At the 5.8-GHz frequency, 1-GW unit and for $2.45-\mathrm{GHz}$ working frequency selected unit is $2.5 \mathrm{GW}$ has been considered. Surprisingly, the lower frequency derived SSPS has lowered size estimation.

Case 4 (@2.45 GHz and 90\% beam efficiency) < case 3(@ $5.8 \mathrm{GHz}$ and 88\% beam efficiency).

The optimized transmitting antenna size has derived in case 4 condition at working frequency $2.45 \mathrm{GHz}$ and a beam collection efficiency of $90 \%$.

\section{Comparative estimation of frequencies 2.45 and $5.8 \mathrm{GHz}$}

Now, case 3 is considered for comparison at the selected frequencies for varying beam efficiency. Similarly, a 1-GW unit is a reasonable choice of comparison study for the reason that it is practically feasible for both operating frequencies.

Comparative transmitting antenna size at frequencies 2.45 and $5.8 \mathrm{GHz}$ is shown in Fig. 9, for the comparison at frequencies 2.45 and $5.8 \mathrm{GHz}$, where this time the same unit size is considered. For higher beam collection efficiency more antenna surface is essential. Notably, there is an apparent size increment with increasing beam efficiency. Figure 10 also shows relatively lower size requirement at $5.8 \mathrm{GHz}$ for the different cases in this study. However, accomplishing higher beam efficiency at lower power unit is relatively simple.

\section{Conclusion}

In this work, satellite solar power station as a base-load power plant is evaluated. Microwave power transfer is essential for SSPS, and to be economically feasible, high efficiency is required. In space section, transmitting antenna size reduction is possible by utilizing optimized interrelated parameters of the system components. In this work, it has been found that microwave power transfer at $5.8-\mathrm{GHz}$ frequency has a size reduction advantage over $2.45 \mathrm{GHz}$ in SSPS. However, this is valid up to the unit size of $1 \mathrm{GW}$ only. Where more than $1 \mathrm{GW}$ unit modules are employed there are feasibility restrictions established for the microwave transmission structure and the design of high power antenna phased array network is found to be impractical. High beam efficiency is utilized for reducing the transmitting antenna size. Thus, microwave power transmission at highest possible beam efficiency has been used. With the efforts of space agencies worldwide, lots of technical issues in SSPS implementation have been covered successfully, and it is found that SSPS has a potential of social acceptance. However, the space launch cost (around $\$ 15.000 / \mathrm{kg}$ ) is very high at present. It is expected that by the year 2040, it will be reduced by a factor of $1.000(\$ 150 / \mathrm{kg})$ and the SSPS will come in action.

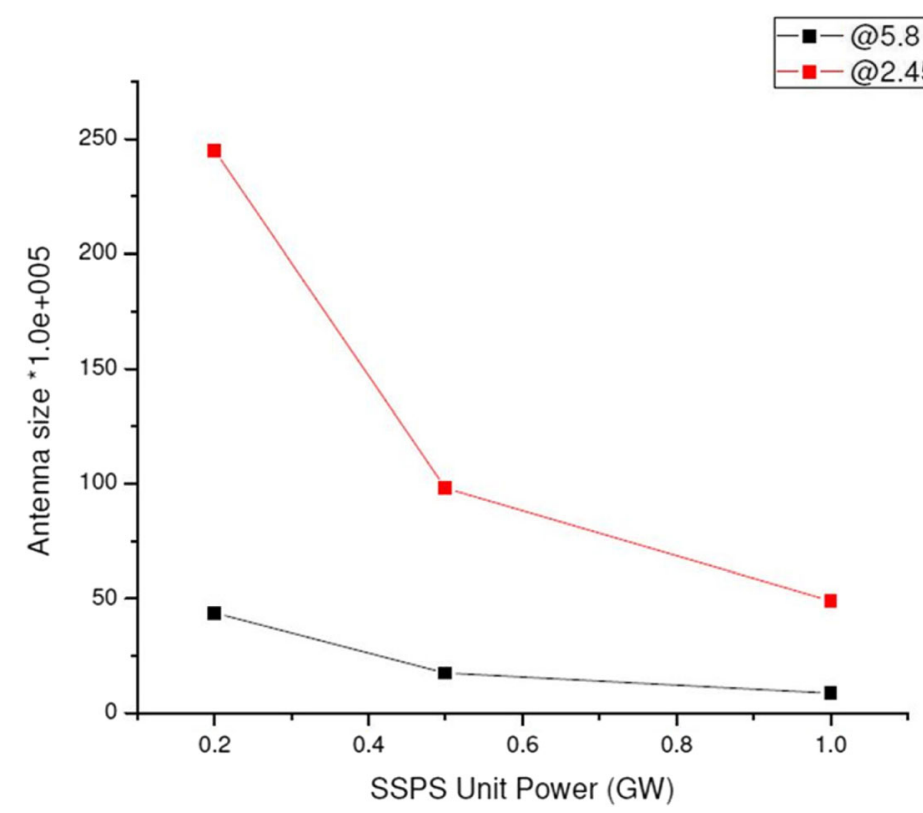

Fig. 10 Antenna size $\left(\mathrm{m}^{2}\right)$ variation with different GW power units 


\section{Authors' contributions}

Both authors read and approved the final manuscript.

\section{Competing interests}

The authors declare that they have no competing interests.

\section{Publisher's Note}

Springer Nature remains neutral with regard to jurisdictional claims in published maps and institutional affiliations.

Received: 4 April 2017 Accepted: 4 June 2018

Published online: 19 June 2018

\section{References}

1. Matsumoto H, Hashimoto K, editors (2007) Report of the URSI Inter Commission Working Group on SPS, URSI, 2006, available at http://www. ursi.org.

2. Landis GA (2012) Solar power satellites. In: Sayigh A, editor. Comprehensive Renewable Energy, Vol 1, pp. 767-774. Oxford: Elsevier

3. Gallagher KS, Holdren JP, Sagar AD (2006) Energy-technology innovation. Annu Rev Environ Resour 31:193-237. https://doi.org/10.1146/annurev. energy.30.050504.144321

4. Biggart N, Lutzenhiser L (2007) Economic sociology and the social problem of energy inefficiency. Am Behav Sci 50:1070-1087. https://doi.org/10.1177/ 0002764207299355

5. Wilson C, Dowlatabadi H (2010) Models of decision making and residential energy use. Annu Rev Environ Resour 32:169-203. https:/doi.org/10.1146/ annurev .energy.32.053006.141137

6. Nisbet MC, Scheufele DA (2009) What's next for science communication? Promising directions and lingering distractions. Am J Bot 96:1767-1778. https://doi.org/10.3732/ajb.0900041

7. Stevenson F, Leaman A (2010) Evaluating housing performance in relation to human behaviour: new challenges. Build Res Inf 38:437-441. https://doi. org/10.1080/09613218. 2010.497282

8. Glaser PE, Davidson FP, Csigi K (1998) Solar Power Satellites. Praxis Publishing Ltd, West Sussex

9. Brown WC (1984) The history of power transmission by radio waves. IEEE Transactions on Microwave Theory and Techniques 32:1230-1242

10. Brown WC (1992) Beamed microwave power transmission and its application to space. IEEE Trans Microwave Theory Tech 40:1239-1250

11. Chaudhary K, Vishvakarma BR (2011) Comparative Study of Rectenna Configurations for Satellite Solar Power Station, vol 7, pp 2-6

12. Kumar D, Chaudhary K (2016) High-efficiency rectenna design for satellite solar power station. In: 2016 IEEE Uttar Pradesh Section International Conference on Electrical, Computer, and Electronics Engineering (UPCON) IEEE, pp 546-550

13. Flournoy DM (2012) Solar Power Satellites. Springer, NY

14. NASA, US DO (1978) Satellite power system, concept development, and evaluation program. Reference system report

15. Chaudhary K, Vishvakarma BR (2010) Feasibility study of LEO, GEO and Molniya orbit based satellite solar Power Station for some identified sites in India. Adv Space Res 46(9):1177-1183

16. Brown WC (1973) Satellite power stations, a new source of energy. IEEE Spectr 10:38-47

17. Nizhnik O (2012) Global high-power RECTENNA site selection. Energy Research Journal 3:12-19. https://doi.org/10.3844/erjsp.2012.12.19

18. Lin JC (2002) Space solar-power stations, wireless power transmissions, and biological implications. IEEE Microw Mag :36-42

19. Shinohara N, Matsumoto H (2004) Microwave Power Transmission System with Phase and Amplitude Controlled Magnetrons. In: Proceedings of 2nd International Conference on Recent Advances in Space Technologies (RAST 2005), Istanbul, pp 28-33

20. Shinohara N, Matsumoto H (1998) Experimental study of large Rectenna Array for microwave energy transmission. IEEE Transactions on Microwave Theory and Techniques 46:261-268

21. Friis HT (1946) A note on a simple transmission formula. Proc IRE 34:254-256

\section{Submit your manuscript to a SpringerOpen ${ }^{\circ}$ journal and benefit from:}

- Convenient online submission

- Rigorous peer review

- Open access: articles freely available online

- High visibility within the field

- Retaining the copyright to your article 